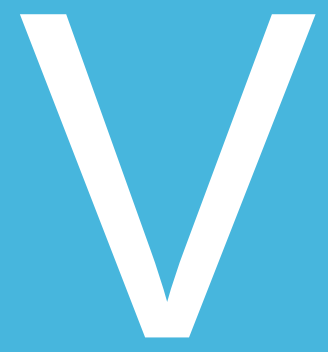

\title{
EVALUACIÓN CRÍTICA DE LA TEORÍA DE LA JUSTICIA DE JOHN RAWLS
}

\section{Critical evaluation of the theory of justice of John Rawls}

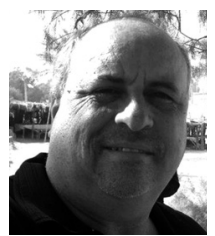

\section{Fernando Aranda Fraga}

El autor es doctor en Filosofía, profesor y licenciado en la misma disciplina por la Universidad Católica de Santa Fe, Argentina. Se desempeña actualmente como decano de la Facultad de Humanidades, Educación y Ciencias Sociales de la Universidad Adventista del Plata; asimismo, es profesor e investigador de la Escuela de Graduados en la misma universidad. Ha sido profesor de posgrado de la Facultad de Filosofía y Letras de la Universidad de Buenos Aires y profesor invitado de posgrado de la Universidad de Montemorelos, Nuevo León, México. Ex director de Enfoques, revista de filosofía con referato. Ex director de Investigación y Publicaciones de la Universidad de Montemorelos (2009-2011) y de la Universidad Adventista del Plata (1998-2008). Evaluador de proyectos de investigación del CONICET (Consejo Nacional de Investigaciones Científicas y Técnicas), Universidad de Buenos Aires, Universidad del Centro Educativo Latinoamericano y Universidad Católica de Santa Fe. Ha publicado más de 80 artículos en revistas especializadas y libros con referato de países de América y Europa sobre Filosofía Política y Ética Jurídica. Además de Argentina, residió varios años en Estados Unidos, España y México. 


\section{Resumen}

Bajo una fuerte influencia de la herencia kantiana, predominante en gran parte de la ética del siglo XX, Rawls diseña una teoría de la justicia cuya máxima pretensión es la de ser imparcial, teoría mediante la cual intenta refutar a las dos corrientes éticas predominantes en su tiempo: utilitarismo e intuicionismo. El neocontractualismo de John Rawls surge en el espectro de la filosofía política contemporánea como un liberalismo de base amplia, cuya principal finalidad es brindar un marco pluralista, capaz de regular la impartición de justicia en una sociedad bien ordenada. En la concepción rawlsiana, la prioridad de lo justo sobre lo bueno estaría denotando una voluntad de asumir una opción de la ética y de la justicia amplia y concurrente, pero carente de teoría moral sustantiva, acorde con el espíritu de una época vacía de contenidos antropológicos capaces de explicar con propiedad la realidad humana y social.

Palabras clave: Rawls, justicia, imparcialidad, liberalismo, contractualismo, consenso

\section{Abstract}

Under the strong influence of the dominant Kantian legacy in much of the twentieth century ethics, Rawls designs a theory of justice whose highest aspiration is to be impartial, whereby theory attempts to refute the two dominant ethical currents in his time : utilitarianism and intuitionism. The neocontractualism of John Rawls arises in the spectrum of contemporary political philosophy as a broad-based liberalism, whose main purpose is to provide a pluralistic framework, capable of regulating the delivery of justice in a well ordered society. In Rawls, the priority of the right over the good would be signaling a willingness to take a choice of ethics and justice and concurrent broad but lacking in substantive moral theory, in the spirit of an era devoid of anthropological content able to properly explain human and social reality.

Keywords: Rawls, justice, fairness, liberalism, contractualism, consensus 
Hasta mediados del siglo XX, los estudios dedicados a metaética constituyeron la preocupación más marcada por parte de la corriente analítica en esta disciplina filosófica, dejando de lado los problemas sustanciales juzgados, por entonces, como carentes de sentido. John Rawls, aún siendo heredero de esta corriente filosófica, impulsa un nuevo desarrollo, retornando al carácter sustantivo de la ética, pero haciéndolo desde un framework cuya base política será la democracia liberal, su metodología el contractualismo, y el contenido un constructivismo pretendidamente exento de supuestos metafísicos, bajo la influencia de su herencia kantiana, aunque con fuertes connotaciones hobbesianas y rousseanianas. Con estos elementos, Rawls diseña una teoría de la justicia cuya máxima pretensión es la de ser imparcial, teoría mediante la cual intenta refutar a las dos corrientes éticas predominantes en su tiempo: el utilitarismo y el intuicionismo. A esto sumará su intención manifiesta de que una sociedad, para estar bien ordenada, será aquella en la cual prevalezca el derecho (Right) por encima del bien (Good). Solo entonces será posible, según el filósofo harvardiano, la existencia de una sociedad pluralista, donde puedan cumplirse los fines de la democracia liberal, lo cual no significará otra cosa, sin más, que la introducción del bien liberal en su pretendida aséptica teoría imparcial de la justicia.

El neocontractualismo de John Rawls aparece en el espectro de la filosofía política contemporánea como un liberalismo de base amplia, afín a la socialdemocracia europea, en su matizada versión estadounidense, cuya principal finalidad es brindar un marco pluralista, en función del establecimiento de una "sociedad bien ordenada". En la concepción rawlsiana, la prioridad de lo justo sobre lo bueno estaría denotando una voluntad de asumir una opción de la ética y de la justicia amplia y concurrente, pero carente de teoría moral sustantiva, acorde con el espíritu de una época vacía de contenidos antropológicos, capaces de explicar con propiedad la realidad humana y social.

El "consenso traslapado" (Overlapping Consensus) concepto del que finalmente se vale Rawls para acercarse a los comunitaristas ${ }^{1}$ - quienes más lo contradijeron con sus certeras críticas hacia los fundamentos de su teoría de la justicia-, termina siendo un instrumento al servicio de una ideología política que ha optado por la preeminencia de determinados valores ordenados a su fin. ${ }^{2}$

\footnotetext{
${ }^{1}$ Los principales filósofos comunitaristas que confrontaron sus ideas con Rawls fueron: Michael Sandel, Charles Taylor, Michael Walzer y Alasdair Maclntyre.

${ }^{2}$ Con respecto al consenso superpuesto acerca de una teoría del bien entre grupos pertenecientes a diversas concepciones del mundo y/o religiosas, véase Bellah, R., Madsen, R., Sullivan, W., Swidler, A., \&. Tipton, S. (1982). The Good Society. New York: Vintage Books, 180, 181.
} 


\section{La tradición en la cual se inserta el proyecto de Rawls}

El proyecto filosófico rawlsiano es heredero del movimiento ilustrado $y$, como tal, se inserta en la tradición racionalista del pensamiento. Pero, aun así, reconoce algunos importantes límites que han sido puestos sobre el tapete con el advenimiento de la posmodernidad. En una época en que ya no hay fundamentos últimos sobre los cuales asirse, se ha resquebrajado todo un mundo de seguridades. La reconstrucción de la razón práctica deberá ser llevada a cabo en condiciones diferentes a las de Kant. Está claro, por ejemplo, el abierto rechazo que hace Rawls de la metafísica kantiana, quedándose solamente con su teoría moral empírica. ¿Qué le queda, entonces, a esta razón? Acorde con el giro pragmático-lingüístico que ha tomado el pensamiento, apenas quedan ciertos mecanismos lógico-formales que han de servir para justificar la existencia de un pequeño núcleo de máximas y de normas. Para Rawls, queda a salvo el intento de separar la facticidad de la validez y de apelar a la imparcialidad, hacia lo cual acometerá a partir de su concepción sustantiva de la justicia. Surge, entonces, la pregunta crítica central: ¿hasta dónde y desde dónde será posible esta apelación a la imparcialidad?, y otra aún más profunda: ¿qué queda de la ética una vez recortado - si es resueltode su ámbito el problema de la justicia?

\section{Un paralelismo limitado entre Kant y Rawls}

Rawls se declara, en muchos de sus escritos, bajo la influencia de la moral kantiana. Sobre todo cabría afirmar esto del primer Rawls, si es posible establecer una división entre dos períodos un tanto diferenciados en nuestro autor. $^{3}$

En lenguaje rawlsiano, diversas nociones propias de la ética kantiana son analizadas y hechas suyas, a partir de sus propios puntos de vista e intereses. Por ejemplo, para comenzar, luego de su afirmación antes citada, que la fuerza de la ética de Kant radica en algo diferente de su generalidad y universalidad (Rawls, 1971, N. ${ }^{\circ} 40$, p. 25) ${ }^{4}$, Rawls (1971), enfatiza el hecho de que el filósofo alemán comienza "con la idea de que los principios morales

\footnotetext{
“"Quizás la más reconocida recreación de la teoría contractual kantiana sea la presentada por la teoría de la justicia de John Rawls. Esta resurrección rawlsiana de la tradición contractual kantiana no solo ha estimulado una serie de lo que ha sido dado a conocer como los pensadores 'contractualistas', incluyendo a pensadores como Brian Barry and T. M. Scanlon, sino además ha producido una nueva tradición de anticontractualistas conocidos como los comunitaristas, a quienes analizaremos en la segunda parte de este capítulo". Boucher, D. \& Kelly, P (1994). The Social Contract from Hobbes to Rawls. Routledge: London, 8.

${ }^{4}$ Se utilizará siempre la versión original inglesa, a menos que se indique otra cosa; la primera cifra se refiere al parágrafo (\#) y la siguiente al número de página correspondiente.
} 
son objeto de elección racional". Tales principios operan como una ley moral mediante la cual los hombres son capaces de autogobernarse, racionalmente, en un estado ético. Así es como una filosofía moral se convierte en el estudio de una concepción que no es más que el resultado de una decisión racional convenientemente definida (Rawls, 1971). Como consecuencia de semejante idea - continúa Rawls - se obtiene que desde el momento en que consideramos los principios morales como un "reino de fines", dichos principios "deben no solo ser aceptados por todos, sino también públicamente conocidos". "Finalmente, Kant supone que tal legislación moral ha sido acordada bajo condiciones en las cuales los hombres han sido caracterizados como seres libres y racionales" (Rawls, 1971, N. $\left.{ }^{\circ} 40,252\right)$. Y aquí viene la aplicación propiamente rawlsiana de estas nociones kantianas asimiladas, porque el filósofo de Harvard se aventura a declarar que su "descripción de la posición original es un intento de interpretar tal concepción", si bien matiza su declaración, afirmando que él no desea "probar su interpretación sobre la base de los textos de Kant" (Rawls, 1971). Aun cuando pueda haber quienes deseen leer a Kant de manera diferente, su propia idea e intención es que las observaciones que habrá de realizar a continuación de su exposición, bien podrían entenderse como sugerencias que permitan "relacionar la justicia como imparcialidad, con el punto cúlmine de la tradición contractualista en Kant y en Rousseau". (Rawls, 1971).

A renglón seguido, Rawls hace un paralelo entre la argumentación kantiana sobre la concepción autónoma de la ética, y su propia noción del "velo de ignorancia" [the veil of ignorance]. Según Rawls, para Kant, una persona, para actuar moralmente, debe elegir sus principios de acción, como "la expresión más adecuada posible de su propia naturaleza, como un ser libre y racional". Tales principios no se adoptan debido a la posición social que ellos ocupan, ni tampoco según el tipo de sociedad en que viven, ni por los dotes que naturalmente poseen, ni según las cosas específicas que desean. "Actuar según tales principios sería hacerlo en forma heterónoma". La analogía mencionada está dada, según Rawls, en que "el velo de ignorancia priva a las personas situadas en la posición original [the original position], del conocimiento que los capacitaría para elegir principios en forma heterónoma". Así es como las partes implicadas, en el contrato social rawlsiano, realizan en forma conjunta sus elecciones, "como personas libres, iguales y racionales, sabiendo solamente que las tales circunstancias dan lugar al surgimiento de la necesidad de los principios de justicia" (Rawls, 1971). 
Rawls asegura que las condiciones mencionadas en su propia teoría contractual aparecen con claridad en los escritos éticos kantianos, tomados en conjunto, lo cual hace de su teoría algo muy cercano a la de Kant. Especialmente coloca la fuerza de su argumentación en el hecho de que "los principios de su accionar no dependen de contingencias naturales o sociales, como así tampoco reflejan sus respectivos planes de vida ni las aspiraciones que los motivan" (Rawls, 1971). Es por ello que Rawls llega a afirmar que "los principios de justicia son, además, imperativos categóricos en el sentido kantiano". Y entonces pasa a definir lo que el filósofo de Königsberg entiende por "imperativo categórico": "...un principio de conducta que se aplica a una persona en virtud de su naturaleza como ser libre, igual y racional. La validez del principio no presupone que uno tenga un deseo o fin particular" (Rawls, 1971, N. $\left.^{\circ} 40,253\right)$. Contrariamente, ante un imperativo hipotético, se "asume que este nos conduce a dar ciertos pasos como un medio efectivo para lograr un fin específico" (Rawls, 1971). Si se deseara alguna cosa particular, ya sea que se trate de algún tipo de sentimiento o de placer, el imperativo que a esto corresponde sería de carácter hipotético. Por el contrario, continúa Rawls, "el argumento para los dos principios de justicia no supone que las partes tengan fines particulares, sino solo que ellos desean ciertos bienes primarios" (Rawls, 1971). Asegura Rawls que estos bienes, que él llama "primarios", son cosas razonables de querer, cualquiera sea el fin que cada particular desee para sí, puesto que desear estos denominados "bienes primarios" [primary goods] es algo propio de la naturaleza humana, racional misma, lo cual existe siempre y no interfiere con los fines particulares que cada cual pueda tener y de hecho tiene (Rawls, 1971).

"La preferencia por los bienes primarios es derivada, entonces, solo a partir de la hipótesis más general acerca de la racionalidad y las condiciones de la vida humana. Actuar conforme a los principios de justicia es hacerlo a partir de imperativos categóricos en el sentido de que estos se aplican a nosotros cualesquiera sean nuestros fines particulares. Esto refleja simplemente el hecho de que ninguna contingencia aparece como premisa de sus derivaciones" (Rawls, 1971).

También afirma Rawls que su presuposición acerca del "desinterés mutuo concuerda con la noción kantiana de autonomía proporcionando otro fundamento más para esta condición", por lo cual, concluye: "ahora podemos agregar que de esta presuposición sobre el desinterés mutuo se 
sigue la libertad que rige en la elección de un sistema de fines particulares", pues el marco de libertad existente en el momento de la "adopción de una concepción sobre el bien está solamente limitado por principios que se deducen a partir de una doctrina que no impone restricciones previas sobre tales concepciones" (Rawls, 1971, N. $\left.{ }^{\circ} 40,254\right)$. Para esto sirve la presuposición sobre el desinterés mutuo que hay en la posición original; es lo que da soporte a esta idea. Restringir sus fines en algún sentido u orientación específica sería restringir de manera arbitraria la libertad reinante en dicha situación. Además, continúa argumentando Rawls: "si se concibiera a las partes como altruistas, o persiguiendo ciertos tipos de placeres, entonces los principios elegidos se aplicarían [...] solo a personas cuya libertad quedaría restringida a elecciones compatibles con el altruismo o el hedonismo" (Rawls, 1971). Tal concepción sobre el bien y las restricciones que le son impuestas a priori, a decir de Rawls: "son el resultado de una interpretación de la situación contractual que no coloca limitaciones previas sobre lo que los hombres puedan desear". De este modo, "hay una multitud de razones para motivar la premisa - propuesta por Rawls - del desinterés mutuo", y concluye su argumentación - mediante la cual busca demostrar su conexión con el principio kantiano de autonomía-, afirmando que: "esta premisa no es simplemente una cuestión de realismo sobre las circunstancias de justicia o un modo de hacer asequible la teoría, sino que esto además se conecta con la noción kantiana de autonomía" (Rawls, 1971).

\section{El uso que Rawls hace del lenguaje kantiano y su adopción de un "Kant à la carte"}

A renglón seguido, luego de una digresión que Rawls hace en su exposición acerca de una supuesta dificultad en la teoría kantiana, puesta en evidencia por Sidgwick (Rawls, 1971, N. ${ }^{\circ} 40,254-255$ ), Rawls intenta despejarla echando mano de nociones típicas, sumamente fuertes, pertenecientes a la filosofía general y a la cosmovisión kantianas. Nos referimos aquí a conceptos pertenecientes al lenguaje con que Kant acostumbra a expresar sus más caras nociones metafísicas, y que, por tanto, solo encajan dentro de su propia interpretación, que al inicio de su deambular filosófico ha formulado acerca del rango de la ciencia, su división del mundo existente en dos realidades absolutamente diferentes (noúmeno / fenómeno) y la decantación disciplinaria que ha hecho dentro del espectro de lo que hasta el momento era denominado y conocido como "conocimiento científico", negándole este 
carácter al conocimiento metafísico. ${ }^{5}$ Vale la pena detenernos en las propias palabras de Rawls acerca de este aspecto señalado:

"Mi sugerencia es que pensemos la posición original como el punto de vista desde el cual los seres noumenales contemplan el mundo. Las partes, como seres noumenales, tienen libertad total de elegir los principios que deseen; pero tienen también el deseo de expresar su naturaleza como miembros racionales e iguales del reino inteligible, precisamente con esta libertad de elección, esto es, como seres capaces de observar el mundo de este modo y de expresar tal perspectiva en sus vidas como miembros de la sociedad. Ellos deben decidir, entonces, mediante qué principios han de conducirse, conscientemente, durante todos los días de su vida, a fin de manifestar de la mejor manera posible esta libertad en sus comunidades, revelando completamente su independencia de las contingencias naturales y accidentes sociales. Ahora, si el argumento de la doctrina contractual es correcto, estos principios son, obviamente, aquellos que definen la doctrina moral o, más precisamente, los principios de justicia para las instituciones y los individuos. La descripción de la posición original interpreta el punto de vista de los seres noumenales, lo cual significa que son seres libres e igualmente racionales. Nuestra naturaleza como tales seres se muestra cuando actuamos a partir de principios que elegiríamos cuando esta naturaleza es reflejada en las condiciones que determinan la elección. De tal manera los hombres exhiben su libertad e independencia de las contingencias naturales y sociales, actuando de un modo en que ellos podrían reconocer en la posición original” (Rawls, 1971, N. ํ 40, 255-256).

Rawls señala que quienes interpretan la ética kantiana como una doctrina moral de leyes, no han logrado entenderla, pues queda claro, según Rawls, que el propósito de Kant "es profundizar y justificar la idea rousseauniana de que la libertad consiste en actuar conforme a una ley que nos damos a sí mismos, lo cual no nos conduce hacia una moral de leyes austeras, sino a una ética de respeto mutuo y autoestima" (Rawls, 1971, N. ${ }^{\circ}$ $40,256)$. Y en nota al pie Rawls afirma que para confirmar su interpretación puede verse lo que Kant afirma sobre educación moral en la Critica de la razón práctica, 2. ${ }^{\text {a }}$ parte (Rawls, 1971 , nota al pie N. ${ }^{\circ} 32$ ).

${ }^{5}$ Es interesante recordar aquí que en 1985 Rawls publica un artículo que ha de resultar paradigmático en cuanto a la comprensión que él pretende de su propia teoría. Nos referimos a "Justice as Fairness: Political not Metaphysical", trabajo escrito bajo la intención de que sus intérpretes traten de evitar ver en su teoría cualquier atisbo de conocimiento de carácter metafísico y restringirla, así, a mera teoría sobre práctica política, con lo cual, en otras palabras, Rawls le enviaba un mensaje a cualquier intérprete de su pensamiento que pusiera en evidencia presuposiciones subyacentes e inevitables de tipo metafísico, ontológico y hasta antropológico. 
A todo esto, agrega Rawls en este mismo parágrafo 40, que su constructo de la posición original "puede verse, entonces, como una interpretación procedimental de la concepción kantiana de autonomía y del imperativo categórico" (Rawls, 1971). En esta posición se eligen los principios reguladores del reino de los fines, así como la descripción de la situación explica el sentido por el cual expresamos nuestra naturaleza como seres libres, iguales y racionales que somos, al actuar según tales principios. Tales nociones - continúa Rawls - ya "no son más puramente trascendentales y carentes de conexiones explicativas de la conducta humana. [...] Es cierto que me he desviado de la concepción de Kant en varios aspectos [...]; pero dos aspectos deben ser notados" (Rawls, 1971, N. $\left.{ }^{\circ} 40,256-257\right) .: 1$ ) "He asumido que la elección de la persona como un ser noumenal es una elección colectiva", y la relevancia de esto radica en que los principios elegidos han de ser aceptados por el resto, desde el momento en que todos son seres libres y racionales, "cada uno debe tener igual oportunidad para adoptar los principios públicos de la comunidad ética", lo cual "significa que, como seres noumenales, todos consienten con estos principios". ${ }^{6}$ 2) "He dado por sentado que todo lo que saben las partes es que ellos están sujetos a las condiciones de la vida humana. Al estar en las circunstancias de la justicia, se encuentran situados en el mundo junto a otros hombres quienes, como ellos, enfrentan limitaciones tales como la escasez moderada y las demandas de la competencia" (Rawls, 1971, N. $40,257)$. Estas restricciones naturales constituyen la base desde la cual son elegidos los principios que han de regular la libertad (Rawls, 1971). En cambio, la libertad de otras inteligencias, tales como Dios, por ejemplo, no entra en esta concepción, dado que su tipo de libertad no está sujeta a semejantes condiciones (Rawls, 1971). Rawls agrega que parecería que Kant cree que su doctrina se aplica a todos los seres racionales, incluyendo entre estos a Dios y a los ángeles. ${ }^{7}$ De ser así, la situación social que ocupan los hombres en el mundo aparentemente no jugaría rol alguno en cuanto a la determinación de su teoría sobre los primeros principios de justicia (Rawls, 1971, N. ${ }^{\circ} 40,257$ ). Rawls concluye el parágrafo en el que se ha dedicado a mostrar la raigambre kantiana de su teoría y sus principales puntos de contacto, con la afirmación

${ }^{6} /$ bid. Rawls afirma a continuación que más adelante ha de definir el sentido por el cual este acuerdo unánime se constituye en la mejor expresión de la naturaleza de cada ser singular, a lo cual se dedica en el \# 85. Por el momento afirma que tal naturaleza colectiva de la elección no deja a un lado los intereses particulares de las personas, cuestión que ahora decide no abordar.

${ }^{7}$ Con esto último se denota que hay en Rawls una gran confusión en lo que respecta a la metafísica de Kant y el lugar que ocupan en su cosmovisión los seres que no están expuestos, o mejor dicho mediados, por una intelección dependiente de las coordenadas espacio-temporales y las restantes doce categorías, mecanismos gnoseológicos, solamente aplicables al mundo fenoménico, que el filósofo alemán desarrolla en la Crítica de la razón pura. 
de que él mismo realmente no cree en esta última breve descripción de la ética kantiana, en relación con la naturaleza de los seres noumenales, "pero continúa- yo no puedo discutir aquí este asunto. Es suficiente decir que si yo estoy confundido, la interpretación kantiana de la justicia como imparcialidad es menos fiel a las intenciones de Kant que aquello que yo estoy actualmente inclinado a suponer (o imaginar)" (Rawls, 1971).

Así fue como la noción de "autonomía de la voluntad", su libertad e independencia de nociones del bien, dio pie para que moralistas posteriores a Kant introdujeran la noción de "autonomía absoluta". A partir de esta autonomía el hombre se da a sí mismo sus normas. Este es el caso de John Rawls y de muchos otros filo kantianos. Rawls - fundándose en su propia interpretación del kantismo- afirma explícitamente no partir de ninguna concepción del bien (Rawls, 1971, N. ${ }^{\circ} 40,252-254$ ). Esto le permitirá tener la ventaja de coincidir con una pluralidad de concepciones acerca de lo que es bueno y con un sinnúmero de proyectos de vida.

En su última etapa, Rawls presenta un intento de explicación acerca de cómo es posible el entendimiento entre diferentes concepciones del bien, ante su postulado de que los principios de justicia funcionan como un marco a priori procedimental, para lo cual introduce la noción de "consenso superpuesto", que reemplaza a la de "equilibrio reflexivo" que había dominado en la $T J .^{8}$

\section{Crítica de los principales supuestos de la teoría de la justicia como imparcialidad}

Como en toda exposición crítica de una determinada teoría -en este caso la rawlsiana concepción de la justicia, y por ende de su noción de "sociedad bien ordenada" - resulta elemental tratar de identificar las presuposiciones en la que está fundada. ¿Cuáles son los supuestos más fuertes implicados en la concepción de la justicia como imparcialidad? Lo que aquí, en definitiva, nos importa son las restricciones que impone Rawls a su teoría, mediante el enunciado de la primera y segunda reglas de prioridad.

\footnotetext{
${ }^{8}$ Rawls asentará estas nociones en varios de sus artículos, tales como: "Justice as Fairness" (1957); "The Independence of Moral Theory" (1975); “A Kantian Conception of Equality" (1975); "Kantian Constructivism in Moral Theory" (1980); "The Idea of an Overlapping Consensus" (1987); "The Priority of Right and Ideas of Good" (1988), "The Domain of the Political and Overlapping Consensus" (1989), etc.
} 


\section{Sobre la prioridad de la justicia y el constructo del artificio de la que esta deriva}

Los problemas inherentes a las reglas de prioridad establecidas - dogmáticamente, pues no están fundados más que en un criterio pura y exclusivamente formal, como lo es el denominado "orden lexicográfico", por Rawls-, han sido tratados por filósofos políticos contemporáneos de Rawls, tales como Hart, Sandel y Taylor, aunque desde diversos ángulos, puntos de vista y horizontes axiológicos. Sin embargo, este tamaño talón de Aquiles implícito y de carácter condicionante de toda la teoría rawlsiana, no ha sido muy tenido en cuenta por otro gran crítico de Rawls, en este caso un representante de habla hispana, como lo es el filósofo español Antonio Millán Puelles. Asimismo, vale la pena ver qué alega el destacado pensador respecto de los dos principios de justicia y de la totalidad del constructor - o artificioen sí de la concepción rawlsiana de la justicia y cómo juzga de utilitarista la elección que los individuos, situados en la posición original, hacen sobre los principios de justicia que han de elegir. En ello, quizás, es donde podamos encontrar la razón del por qué Rawls, al efectuar la crítica de la posición clásica del utilitarismo, no coloca a Hume entre aquellos a quienes critica, con lo cual se explicaría la influencia, que "circunstancias de la justicia" mediante, y demás elementos propios de su noción constructivista de la ética, habría ejercido el escocés ilustrado sobre el filósofo harvardiano:

“[...] En lo tocante a la concepción de la justicia según la determinan los dos principios que señala Rawls, puede decirse que no cabe oponer ningún reparo al primero de ellos, i. e., al que requiere la igualdad en la atribución de los derechos y deberes básicos. Este principio no puede dejar de parecer un auténtico principio de justicia si se tiene presente que los derechos básicos de los hombres que integran la sociedad son los correspondientes a su específica índole de personas humanas, cabalmente en lo que en todas ellas es idéntico, ya que ninguna es más persona, ni tampoco menos, que cualquiera de las demás. (Naturalmente, el uso de esos derechos, que son otras tantas libertades civiles, y el ejercicio de esos deberes - no los derechos ni los deberes mismos en cuanto tales- admiten la sujeción a condiciones y limitaciones provenientes de la exigencia de que todos los miembros de la sociedad se mantengan en un recíproco respeto)" (Puelles, 1995, 255-256). 
Tal como se percibe en la cita anterior, tomada del texto citado de Millán Puelles, y según lo que hemos comentado al introducir la cita, el filósofo español se detuvo simplemente en analizar y verificar si procede o no tildar como justos al primero y al segundo de los principios de justicia enunciados por Rawls (Puelles, 1995). Por eso puede afirmar, en una primera aproximación a la teoría rawlsiana que, a su entender, los juicios que ha efectuado sobre cada principio tomado por separado, sin tener en cuenta la cuestión que los ha de regular, acerca de la prioridad lexical, son más que acertados $^{9}$, ya que precisamente la gran crítica que en general se efectúa a la concepción rawlsiana de la justicia, en cuanto se refiere específicamente al primero de los principios, parte del hecho de la mencionada prioridad, que Rawls establece dogmáticamente, sin fundamentación sólida. Obviando esto, Millán Puelles puede arribar a una conclusión positiva acerca del atributo de justicia del que Rawls habría bien dotado al primero de los principios, pues es un asunto que se relaciona directamente con el derecho a la igualdad (Puelles, 1995, 255-256).

Ahora bien, si observamos más de cerca lo que afirma el filósofo español cuando critica la carencia absoluta de justicia inherente al segundo de los principios, percibimos lo apropiado y profundo de su análisis. Porque en rigor de verdad, no es sino una forma de utilidad o provecho personal lo que Rawls busca al enunciar cómo a su juicio se estaría haciendo justicia compensando las desigualdades naturales. De modo que hay en Rawls, de acuerdo con el enunciado de su segundo principio, un retorno al principio utilitario (Puelles, 1995, 256).

Pero la crítica en este punto resulta consolidada, finalmente, cuando - siguiendo siempre a Millán Puelles - caemos en la cuenta de que Rawls ha confundido los valores, y termina llamando "justicia" a una asignación de valor que, sin dejar de ser válida, encomiable, o lo que de esta se quiera afirmar, tiene que ver con otra virtud muy diferente del ser humano, que sería la "generosidad", o "caridad" (Puelles, 1995). Tiene razón Puelles $(1995,256)$, cuando dice que "lo justo al distribuir las ganancias logradas

\footnotetext{
${ }^{9}$ Pero todo esto queda automáticamente anulado, cuando Rawls anuncia la puesta en juego del orden lexicográfico de los principios, de modo que la segunda de las virtudes que aparece en el juego, quedará siempre restringida y limitada por la buena — o mala - voluntad de las partes, que pueden moverse libremente - de acuerdo con lo enunciado en el primero de los principios - el cual impone como necesariamente prioritario el valor de la libertad, con lo cual termina prevaleciendo en la teoría rawlsiana de las regulaciones sociales la ideología liberal. Porque, en definitiva, cuando los individuos han quedado a merced de este prioritario primer principio como rector de la sociedad, la aplicación posterior del segundo de los principios, para que realmente sea efectiva, debería ser impuesta como obligatoria, bajo una ley que sancionara su incumplimiento, lo cual termina siendo un absurdo, de acuerdo al principio lexical que rige el orden de aplicación de los principios elegidos en el momento del pacto.
} 
con la cooperación es que reciba más quien voluntariamente aporta más", ya sea que tal acción vaya en una mejoría o no de la situación de los menos afortunados. La caridad, de la cual gozarían, así, los menos aventajados de la sociedad, dista mucho de ser tomada como algo igual o semejante a la justicia; por tanto, lo que Rawls tendría que hacer, al introducir este cambio de virtudes en su segundo principio, sería modificar la denominación que le dio a su teoría ética, pues, al trabajar con dos virtudes, ya deja de ser una "teoría de la justicia", para convertirse, en todo caso, en una "concepción moral hasta con ciertos visos de compreensibilidad y conmensurabilidad- sobre la aplicación secuencial de las virtudes". Esto incluso, si bien alteraría sus propósitos originales e ideales de estirpe liberal, convertiría, como dijimos, su teoría antes restringida a la justicia en las instituciones, en una ética para la convivencia social - siempre de carácter contractual, por supuesto, pues los principios morales, cualesquiera sean las virtudes en juego, surgen de la hipotética y ficticia "posición original" en que están situadas las partes.

"Pero el segundo de los principios de Rawls no es un auténtico principio de justicia. Para que todos los que cooperan lo admitan-bajo el velo de la ignorancia-es necesario que cada cual lo considere como el más ventajoso para él en el supuesto de que él mismo se encontrase en una situación desventajosa. Ahora bien, lo elegido de esta manera no es directamente preferido por estimarlo justo, sino por ser considerado útil, provechoso, por y para quien efectúa esa elección. Y, por otra parte, para que de un modo indirecto pudiera parecer justo, sería preciso suscribir la idea de que la justicia-o, cuando menos, una de sus formas-exige hacer lo posible por mejorar la situación de los menos afortunados. Pero tal pretensión no pertenece verdaderamente a la justicia, sino a la generosidad y a la caridad. Solo cabría ligarla a la justicia si se admitiese que verdaderamente son injustas las desigualdades naturales y todas las provenientes de alguna involuntaria contingencia. Mas semejante manera de pensar es por completo absurda, contradictoria, porque lo meramente natural y lo puramente involuntario no pueden calificarse de injustos ni de justos, como quiera que en sí y por sí son moralmente indiferentes, neutros" (Puelles, 1995).

En relación con el dispositivo artificial creado por Rawls, "el velo de ignorancia" 10 , constituido en elemento disparador de la elección axiológica

10“Finalmente, y en lo que toca a la 'inicial situación de igualdad' bajo 'el velo de ignorancia', se ha de tener en cuenta que el desconocimiento-el efectivo también, no únicamente el hipotético-de la posición en que uno está, no anula por sí solo la posibilidad del influjo de esta misma posición; y, en consecuencia, puede permitir una diversidad de opciones-no, por tanto, una unánime elección respecto de los principios por los que básicamente habría de regirse la convivencia. Una desigualdad ignorada, pero existente, no siempre es 
-y su consabida prioridad- cabe recordar aquí, como ya fuera dicho en su momento, que no solo se trata de un supuesto artificial en demasía y absolutamente no demostrado, sino que, además, posee un carácter utópico. Pretende una amnesia de la psiquis, tanto superficial como profunda, que solo cabría lograr mediante técnicas de hipnosis, operadas por expertos, a fin de borrar de un plumazo y a voluntad conocimientos relevantes que se constituyen en elementos molestos o perjudiciales a la hora de tener que elegir los principios y la prioridad que los rige, también ficticia.

\section{El gran supuesto rawlsiano que ha sesgado la pretendida "imparcialidad" de su teoría}

Con el tratamiento que Rawls introduce el problema de la prioridad de los principios, más aún que en el enunciado propiamente dicho que efectúa de los mismos, queda claramente delineada la ideología política que sustenta su teoría. Sin embargo, debemos recordar que tanto los principios como las reglas de prioridad (el orden lexicográfico), son partes componentes de un tipo de expediente político, al cual se acude para dar explicación, ya sea del origen o del mantenimiento de la sociedad civil, cuando el punto de vista adoptado es liberal. Desde luego, como en todo pacto o acuerdo social, desde sus orígenes hobbesianos en la Modernidad, se trata aquí de un contenido contractual acordado entre las partes, o entre los contratantes, si así se prefiere denominar a los que en él toman parte, de carácter plenamente artificial. Recordamos que este tipo de procedimiento en la epistemología política de Hobbes, significaba, sobre todo, promulgar la ruptura con la explicación aristotélica $-y$ tomista - sobre el origen de la sociedad política. Negar la explicación vía natural de la asociación política, significará, obviamente, dar una explicación vía artificial de la misma. Análogamente ocurriría, un siglo más tarde, con el enunciado que hace Hume sobre el carácter - artificial por excelencia- que posee la virtud de la justicia. También aquí hay un esfuerzo

lo mismo que una desigualdad sin resultados en la actividad de elegir. De ahí que con toda razón haya podido escribir R. Spämann: '(...) en la pregunta acerca de lo que cada uno puede querer como máxima de una legislación universal, juega un papel no solo el interés particular del agente, sino también su disposición natural. Este problema se plantea también en la elección inicial-a la que se refiere J. Rawls de un sistema político bajo el velo de la ignorancia. ¿En qué sistema quisiera vivir yo, bajo qué modo de distribuir las oportunidades? Esta pregunta debe hacérsela cada uno a sí mismo sin saber qué lugar ocupa dentro del sistema. De ningún modo conduce eso, sin embargo, a una elección justa. Los hombres son utilizados aquí como jugadores. El jugador propenso a la cautela elegirá un sistema en el que le siga yendo bien incluso cuando las cosas le salgan lo peor posible. Otro jugador se lo juega todo a una carta, arriesga una vida miserable, carente de privilegios, por la posibilidad de ser el gran rey de Persia. Para elegir un orden justo se debe ser ya justo. La justicia de la elección no se puede establecer mediante un cálculo de los intereses bajo condiciones fácticas'. Cf. Felicidad y benevolencia, en la óptima versión de del Barco, J. (1991). Madrid: RIALP, 201-202". Ibid., 257 
por oponerse a lo que tanto Aristóteles como Santo Tomás de Aquino entendían por justicia natural. ${ }^{11}$ El hecho es que con Rawls, además del contenido del expediente contractual mismo, en que se concibe, de suyo, a la justicia en una "sociedad bien ordenada" como algo absolutamente artificial, puesto que se trata de dos principios de justicia acordados por las partes, aparece conjuntamente este criterio jerarquizador de valores - el orden en la aplicación de los principios de justicia- que si no queremos tildarlo de algo meramente artificial, no podrá evadirse del calificativo de ser absolutamente convencional, lo cual no es muy diferente de lo anterior.

Por el momento, es suficiente tomar como punto de partida las palabras del propio Rawls, al finalizar el parágrafo 8, sobre la justificación de la prioridad de los principios. Primeramente se declara en favor de la formulación de una propuesta "razonable y generalmente aceptable para conseguir el acuerdo deseado en los juicios" (Rawls, 1971, N. ${ }^{\circ} 8,42-43$, Nota № 23). Luego agrega que si bien reconoce que "sin duda existen otras maneras [de tratar este problema de la prioridad de los principios], pero no consideraré cuáles podrían ser estas" (Rawls, 1971). En la página 43 de este mismo parágrafo 8 , en tanto argumentaba sobre el significado y la aplicación a su teoría del mentado orden lexicográfico, había ya dado cuenta, un tanto humildemente, sobre lo poco prometedor (Rawls, 1971, N. ${ }^{\circ} 8,43$ ) y hasta quizás ofensivo hacia "nuestro sentido de moderación y buen juicio" (Rawls, 1971), que resulta el criterio que ha propuesto. Mediante este hecho da muestras, a todas luces, de la debilidad inherente que posee como principio de fundamentación de algo tan relevante como lo que aquí está en juego, ni más ni menos que constituirse en medida de jerarquización de valores en una teoría que, además, se ha de proponer como precedente e introductora de toda ética pública posible. Finalmente, en el último párrafo del parágrafo № 9, en el cual presenta su posición acerca de los alcances de una teoría moral, reconoce abiertamente lo insatisfactorio que resulta el criterio de prioridad que ha decidido adoptar: "Es descorazonador, por ejemplo, cuán poco puede ahora ser dicho acerca de las reglas de prioridad; y aunque un ordenamiento lexical puede servir imparcialmente bien para algunos casos importantes, supongo que no ha de resultar completamente satisfactorio" (Rawls, 1971, N. $\left.{ }^{\circ} 9,53\right)$.

Volvamos a lo que expresa en la justificación basada en la derivación

${ }^{11} \mathrm{~A}$ fin de obtener una idea cabal acerca de lo que contemporáneamente se sostiene sobre la concepción naturalista de la justicia y del derecho, ver el análisis que realiza de esta temática Carlos I. Massini Correas, a raíz de la publicación de una obra sobre el tema del catedrático de Oxford John Finnis: Massini Correas, C. (2000). Justicia y derecho en Ley natural y derechos naturales de John Finnis. Sapientia, LV, 207: 557-568. 
del término "lexicográfico", en la citada nota N. ${ }^{\circ} 23$, al pie de la página 42 , del parágrafo 8 , donde, después de haber formulado su definición, y dado cuenta de otros hechos históricos del uso del término, declara Rawls que se trata de un concepto que ocasionalmente ha aparecido en la historia de la filosofía moral sin que se lo hubiera debatido explícitamente (Rawls, 1971, N. ${ }^{\circ} 8,42-43$, Nota N. ${ }^{\circ} 23$ ). Esto abona el terreno, supondrá Rawls, para que él tampoco necesite justificar explícitamente su introducción como criterio jerarquizador, limitándose, simplemente, a presentar una definición formal -ya que no existe otra, por cierto- afirmando que así como las palabras aparecen alfabéticamente ordenadas en un diccionario, puede obtenerse una jerarquización semejante si en lugar de letras: "a", "b", etc., sustituimos estas por números: "1", "2", y así sucesivamente, y graduamos luego los números desde la izquierda hacia la derecha, de manera que el primero ha de tener mayor jerarquía que el segundo en la fila, y así sucederá con los restantes valores numéricos (Rawls, 1971).

El intento de legitimación del orden lexicográfico, al ser aplicado por Rawls a la jerarquización axiológica de sus principios, no pasa de ser insólito por demás. Creemos que, por tanto, afirmar que se reconoce su debilidad, como hace Rawls en las páginas que siguen a la nota citada, es quedarse corto -es lo mínimo que puede hacer alguien que pretende hacer filosofía- y que, quizás solo haya reconocido su precariedad para no asumir posturas que puedan ser tildadas de dogmáticas, ya que insertas en un marco ideológico como lo es el liberalismo político, y a pesar de que, como veremos más adelante, hay ciertos graves presupuestos dogmáticos subyacentes a la teoría misma, dejar pasar como algo desapercibido tamaño supuesto convencional, introducido como si realmente constituyera un axioma, hubiera dado aún mayores muestras de inconsistencia.

El hecho, aquí, es que un criterio como el que Rawls pretende para determinar la jerarquización de los valores implícitos en sus principios de justicia, podrá resultar útil en meros ordenamientos donde lo importante, lo en sí de la cosa, es el orden serial mismo y no lo que representa cada número de orden que, en este caso puntual, se trata de conceptos sumamente fuertes, como son los valores, además de poseer connotaciones políticas y de marcados rasgos ideológicos. Por ejemplo, es posible utilizar un orden serial, o lexicográfico, al asignar números correlativos a un conjunto de personas dispuestas en una columna o una fila, o al ordenamiento de disposiciones, artículos, incisos, etc., en un determinado código, o al listado de alumnos de un mismo curso que se ordenan alfabéticamente, con la finalidad de 
pasarles asistencia, registrar sus notas, etc., de manera que luego sirva para ser transcriptos a otras listas o documentación, ya que ello redundará en un beneficio pura y exclusivamente pragmático que permitirá su rápida ubicación a quien deba efectuar la transcripción, ordenación de legajos en archivos, etc. Pero pretender justificar una jerarquización de valores en tal tipo de procedimientos, que, visto y aplicado a semejante contenido se constituye en una especie de "quinta esencia del convencionalismo", es algo que se percibe como débil en grado sumo, no solo por el sentido común, como dice Rawls, sino por la propia racionalidad humana.

\section{La justicia como imparcialidad: una utopía antinatural}

A todo esto debe agregarse, aunque no existiera el mentado orden lexical de los principios, el hecho de que la generosidad o caridad no es algo susceptible de ser aplicado en forma normativa, por obligación, puesto que el hecho contractual mediante el cual se erigen tales principios se debe a una determinada definición del hombre, que constituye los supuestos que condujeron al pacto originario, puesto que el hombre, aquí, es entendido como un ser "no sociable por naturaleza" (como en todos los contractualistas modernos) e incluso "sin naturaleza", por la corriente neocontractualista en la cual se inscriben Rawls y otros filósofos políticos contemporáneos. Así, la teoría moral rawlsiana, sea por la vigencia del orden lexicográfico que él mismo le ha puesto como principal límite a sus aplicaciones, o sea porque nunca puede ni podrá ser impuesta por la fuerza de la generosidad, resulta inaplicable en la práctica.

\section{Los supuestos (metafísicos) no tematizados en la noción rawlsiana de fairness}

Esta cuestión del procedimentalismo ético plantea ciertos problemas:

1. Su neocontractualismo, como recreación del contractualismo moderno, está asentado en un paradigma secular en el cual la moral se construye a partir de un pacto entre iguales, es decir, mediante un principio meramente convencional.

2. Se trata de una teoría moral construida, basada en conceptos tomados de Hume y de Kant, a saber, básicamente, el convencionalismo implícito 
en el espíritu anglosajón y la noción de autonomía, elevada a carácter de absoluto, respectivamente.

3. A diferencia de la ética formal kantiana, también basada en la autonomía, se niega la dicotomía entre mundo nouménico y mundo fenoménico, que subyacía a la moral kantiana. En última instancia tal distinción seguía siendo el fundamento último de la ética formal, cuyo Imperativo Categórico terminaba apoyándose en una batería de imperativos hipotéticos. Rawls niega cualquier tipo de apoyo sustancial y trascendental a su teoría. El fundamento radica, en primera instancia, en el acuerdo por el cual son aceptados los principios y, en última instancia, en las motivaciones que impulsan a acordar a las partes mutuamente desinteresadas.

4. La autonomía y la noción de "persona moral", de raíz kantiana, según Rawls, permiten subsumir diferentes concepciones del bien. Esto, sin embargo, puede constituir una ventaja, perseguida por Rawls como es sabido, a los fines de servir a una democracia pluralista, pero no la libera de una severa crítica por desentenderse de la búsqueda de un bien objetivo, dejándolo librado a una libre elección de los contratantes.

5. Rawls supone que mediante un correcto procedimiento, como puede serlo la imparcialidad y la situación contractual, pueden obtenerse principios neutrales, objetivos y exentos de supuestos materiales. Pero ocurre que de reglas meramente procedimentales no pueden obtenerse contenidos, en este caso una concepción sustantiva de la justicia. Lo que ocurre es que sí existen supuestos en su teoría, solo que no han sido tematizados, están en forma acrítica. Son contenidos nunca justificados. Por ejemplo, subyace en él una concepción del hombre individualista, atomista y egoísta. Ergo, los principios de justicia no terminan saliendo de un mero procedimiento, sino de una idea de bien que opera como un presupuesto condicionante no implícita ni explícitamente reconocida. ${ }^{12}$

\footnotetext{
12 "No cabe duda de que en la obra de Rawls hay, bajo la forma de una concepción implícita y no reconocida como una creencia específica, una teoría de la naturaleza de la sociedad moderna, inspirada en la ideología liberal. Se expresa por el modo de disyunción que Rawls cree poder introducir entre lo político y lo económico. Esta teoría va ligada a la representación del carácter mercantil propio del mercado (y regulable solo en calidad de tal) de la economía. Esto es congruente con los presupuestos del individualismo metafísico que, a pesar de su dimensión holístico-estructural, domina el conjunto de su pensamiento. Este pensamiento es también el que alienta en la idea de que, los derechos de participación política serían, en parte, negociables a cambio de otras libertades". Bidet, J. (2000). John Rawls y la teoría de la justicia. Pamplona: Bellaterra, 126.
} 
6. Cuando Rawls afirma que su teoría de la justicia es de índole estructural, es decir, aplicable solamente a las instituciones de la sociedad, bien cabe recordar que estas no son entes abstractos, sino que están dirigidas y conformadas por sujetos, con virtudes y defectos, que ejercitan en su tarea institucional sus hábitos y predisposiciones morales, susceptibles de afectar de un modo u otro a las personas que se relacionen con tales entidades. Las instituciones están manejadas por hombres quienes, al disponer reglamentaciones en ellas, lo que hacen no es otra cosa que aplicar sus propios principios morales de justicia, aunque sean consensuados, pero estos nunca surgen de la nada. Además los "yoes" que manejan estas instituciones, nunca son "yoes" aislados, sino seres en interrelaciones comunitarias, entramado natural que Rawls no está dispuesto a reconocer, puesto que tal concepción del sujeto contradeciría los fundamentos mismos del yo liberal que, persiguiendo sus propios fines, es incapaz de perseguir bienes que sean comunes, propios de la comunidad en que está inserto y a la cual, en cierta medida, también se debe como persona humana, dotada de racionalidad y sentido de lo que es bueno, de lo que es ético y de lo que es, por tanto, también justo.

7. La teoría de la justicia rawlsiana tiene como fin político apoyar una concepción pluralista de la sociedad, lo cual es un hecho positivo, según Rawls. Sus críticos comunitaristas creen lo contrario, pero sin entrar a discutir si esto es o no bueno, se presenta ante la vigencia de una teoría moral pluralista el problema de cómo es posible resolver conflictos sin una concepción de qué es lo bueno, o al menos una ética "mínima". Además, ¿cómo se podrá dirimir conflictos entre culturas muy diferenciadas? Si no hay ciertas reglas de convivencia, y no una mera teoría moral soft, ¿cómo será posible mantener la existencia de la sociedad? Si cada uno puede tener su propio plan de vida y su concepción de qué es lo bueno, ¿no caemos en cierto escepticismo y un fuerte relativismo moral?

8. Este relativismo moral se denotaría al situar a Rawls como uno de los valores cardinales del establecimiento de una "sociedad bien ordenada" (algo así como la "paz social" hobbesiana), que no es sino una forma de eficacia, por más que Rawls se empeñe en demostrar, a partir de sus artículos de 1982 en adelante, que su teoría no se refiere a un "modus vivendi" (al modo de Hobbes), sino a un "verdadero" consenso superpuesto o traslapado. 
9. En este caso, la ética jurídica de Rawls tendría un fundamento estrictamente político y no filosófico, con lo cual se produce, así, una politización absoluta de la existencia; las virtudes quedan reducidas al ámbito de lo que es justo y dentro de este a lo que tiene que ver solamente con la justicia pública. Esta, a su vez, está dominada por el marco de las metas y objetivos estrictamente individuales, que solo procuran la búsqueda autointeresada del bien individual, desinteresándose absolutamente por cualquier clase de bienes que pueda ser común. El bien de la comunidad no tiene lugar en la teoría de la justicia como imparcialidad.

10. Una ética basada en una concepción (procedimental) de la justicia, con fundamento político, daría, según Rawls, prioridad a lo justo (Right) y al derecho sobre el bien, o idea del bien (Good). En este último aspecto, cabría aplicar a la teoría ética rawlsiana críticas más o menos similares a las que se le pueden aplicar a los filósofos contractualistas modernos, desde Hobbes en adelante, pasando por otros meramente convencionalistas, como lo fueron Hume, Bentham, Mill y Adam Smith.

11. Finalmente, queda por juzgar la concepción del pluralismo que sostiene Rawls en su segunda y última etapa filosófica, la cual debido a no haber sido especificada en la etapa de su obra $T J$, no significa que no haya estado siempre presente en él. Aparece esto claramente expresado en sus artículos de 1985 ("Justice as Fairness: Political Not Metaphysical"), y de 1987 ("The Idea of an Overlapping Consensus"), ambos publicados más tarde, aunque revisados, como capítulos independientes de su segunda gran obra, Political Liberalism (1993). En ambos trabajos Rawls desea asentar su idea de que cualquier concepción comprensiva del bien, que no vaya en contra de los principios elementales que sostienen las democracias liberales occidentales, puede ser asimilada y aceptada dentro del marco universalista que propone su teoría de la justicia como imparcialidad. Esto le conviene a Rawls, a fin de poder hallar la mayor cantidad de adherentes posibles a su teoría, por un lado, además de presentarse como un pluralista que admite - al más puro estilo de la comprensión negativa de la libertad de los liberales modernos-cualquier idea en tanto y en cuanto no perjudique la conciencia ajena. Pero he aquí que a la hora de ser preciso en cuanto a las concepciones permitidas, Rawls se decanta claramente por una opción, por más que repetidas veces niegue que esto signifique para él que la teoría de la justicia como 
imparcialidad esté basada en los supuestos que tales concepciones comprensivas del bien sostienen. Nos referimos a las teorías del bien del liberalismo representado por Kant y por Mill. Pero este hecho es más desconcertante aún, dada la pretensión Rawlsiana de seguir siendo pluralista a rajatabla, cuando de la lista de las concepciones comprensivas del bien elimina explícitamente aquellas que se presentan como concepciones teleológicas, en sentido fuerte, tales como las doctrinas del bien de Platón, Aristóteles, Santo Tomás de Aquino, etc., por mencionar solo algunos ejemplos de los tantos que existen en el concierto de las teorías éticas. ¿Dónde ha quedado, entonces, su pretendido pluralismo, que no le permite aceptar doctrinas comprensivas que sostienen un sentido y una finalidad para el hombre y la sociedad política que este conforma junto con sus semejantes, y que aspira a la perfección, tanto de este como individuo, así también como ser social? Rawls cae en un nuevo sesgo que lo conduce a la autocontradicción.

\section{Síntesis de los aspectos críticos puntuales más relevantes de la teoría de Rawls}

Para llevar a cabo este repaso puntual de la crítica a ciertos aspectos relevantes de su teoría de la justicia como imparcialidad, dividiremos su tratamiento en dos momentos: a) las cuestiones de índole metaético, y b) las cuestiones involucradas en aspectos de índole ético normativo.

\section{Cuestiones referidas a metaética ${ }^{13}$}

1. Sobre la objetividad débil que Rawls aspira que posea su teoría de la justicia. Esta objetividad solo se basa en la autointeresada aceptación de los pactantes, que a su vez son los destinatarios de los principios y la coherencia interna de estos. Además Rawls abandona la noción de verdad en correspondencia con las estructuras de la realidad. La objetividad de la teoría de la justicia rawlsiana se logra cuando su conjunto de proposiciones alcanzan lo que Rawls denomina como "equilibrio reflexivo", proceso mediante el cual los argumentos son sopesados y balanceados en una justa ponderación. "Dicho más brevemente aún: la objetividad es el resultado de la suma de la coherencia de los principios más su aceptación". Ahora

\footnotetext{
${ }^{13}$ Véase: Massini Correas, C. (2000). Del positivismo analítico a la justicia procedimental: la propuesta aporética de John Rawls. Persona y Derecho, 42, 188-199.
} 
bien, ocurre que según las reglas universales de la lógica, el carácter que poseen las premisas es transferido a las conclusiones. Por tanto, como las premisas jamás fueron justificadas, o lo han sido en forma débil, su carácter no justificado se transmite a las conclusiones. Así, de premisas ficticias, solo podrán obtenerse conclusiones ficticias. Massini Correas menciona que el intento rawlsiano por darle valor normativo objetivo a sus dos principios de justicia, siendo que el acuerdo se funda en normas que fueron instituidas por nosotros mismos, no será posible, entonces, poder hablar de validez objetiva de las normas, de modo que el acuerdo carece de justificación racional suficiente.

2. En relación con el carácter constructivo procedimental $\left(2 .^{\circ}\right.$ supuesto de Rawls, lo que Massini llama "falacia constructivista o procedimentalista") hay que decir que no es posible extraer principios normativos concretos a partir de un mero procedimiento; con ello, Rawls incurre en un paralogismo. Al respecto dice Kaufmann:

“[...] De hecho, este pensamiento de que la pura forma, el deber ser puro, podría producir contenidos y reglas de conducta concretas, que alejen el engaño de la percepción, ha ejercido una gran fascinación en muchos pensadores. Hoy en día se denominan estos intentos mayormente como teorías procesales de la verdad o de la justicia. [...]" (Kaufmann, 1992).

De acuerdo con Kaufmann (1994), "es imposible llegar a contenidos materiales partiendo únicamente de la forma o del procedimiento, o por lo menos contando únicamente con este. Es evidente el carácter circular de la demostración [...]". Rawls pretende que sus principios de justicia tengan valor normativo, por el mero hecho de haber seguido, al hallarlos, determinados procedimientos racionales; a esto él denomina como "justicia procedimental pura", con lo cual incurre en la mencionada falacia. Höffe la denomina "falacia normativista". Esta consiste en la ilegítima pretensión de extraer normas concretas de contenido a partir de normas formales generales. En definitiva, debe ser dicho aquí, junto a Massini Correas, que el valor normativo de los principios de justicia no puede ser extraído exclusivamente de un mero procedimiento racional que ha sido seguido para llegar a ellos. Para que el razonamiento sea correcto, la aceptabilidad de las conclusiones debe seguirse de la aceptabilidad de las premisas, todo lo cual ha de ser demostrado en forma adecuada y no dado por supuesto (Höffe, 1996, 1988). 
3. Resulta muy cuestionable, por dudoso, el carácter ético que puedan poseer los principios de justicia de Rawls, puesto que este pretende derivarla de "la naturaleza estrictamente estratégica del procedimiento seguido para alcanzarlos", es decir, del artificio erigido, en el cual son colocadas personas que, guiadas por el solo autointerés (Parkin, 1985), logran establecer determinados principios éticos de convivencia. Massini Correas afirma que no es posible pasar de un orden ético-instrumental, como lo es el procedimentalismo rawlsiano, al orden ético-normativo, puesto que no existe en Rawls ningún puente que así lo permita. Carlos Nino afirma que "el recurso al autointerés para justificar principios éticos es desconcertante, puesto que una mínima comprensión de las funciones del discurso moral indica que están asociadas con la necesidad de neutralizar el autointerés para salir de la encerrona de situaciones como las del 'dilema de prisioneros' [...]" (Nino, 1992). Höffe señala al respecto que "Rawls pretende deducir los principios de justicia de una elección racional de prudencia", y las prescripciones de prudencia son heterónomas, ya que no son imperativos categóricos, sino hipotéticos, en el sentido kantiano. Justamente son heterónomas por derivar del propio bienestar, por consiguiente "son tributarias de aquello que se opone más netamente al principio moral kantiano" (Höffe, 1988). Aquí Rawls se aparta del kantismo "para caer en la estructura técnico-instrumental de razonamiento propia del utilitarismo y, en última instancia, en la saga de la impostación hobbesiana del pensamiento moral" (Massini Correas, 2000). Así es como, en definitiva, Rawls termina siendo un utilitarista al estilo hobbesiano, relegando su proclamado kantismo y confluyendo en una postura ética heterónoma, debido a que su "prudencia" está fundada en el autointerés, tal como sucedía con Hobbes.

4. Se trata, finalmente, de una metaética estructural, institucional, que no toma en cuenta que el sujeto de los actos éticos es la persona humana. Así, Rawls culmina dejando a un lado las dos dimensiones centrales de la ética, esto es, las motivaciones morales y las concepciones del bien de que están dotados los sujetos. Esto significa desconocer las motivaciones morales de los seres humanos, por lo cual resulta incapacitada para poder entender en base a qué razones actúan los sujetos conforme a los principios morales. Estamos, aquí, ante una ética para sujetos que desconocen quiénes son y cuál es el sentido por el cual obran, hecho que fuera claramente señalado en la crítica desarrollada por Sandel 
(1982). No resulta demasiado creíble que unos sujetos ignorantes sobre su propia condición, puedan luego respetar el acuerdo al que finalmente llegaron en la posición original; más aún cómo se ha de lograr que las partes contratantes puedan respetar un acuerdo cuando, al levantarse el "velo de la ignorancia" las condiciones cambien radicalmente en relación con las que tuvieron lugar al momento de llevarse a cabo el acuerdo. La predicción de Rawls acerca de que las partes respetarán el acuerdo al que han llegado a ciegas, estando ausente en los pactantes — según las propias declaraciones de Rawls - la dimensión de las virtudes personales, es poco creíble, por no decir que se trata de una verdadera utopía. Si son excluidas las virtudes del accionar moral, entonces desaparecen los motivos para que cualquier miembro de una sociedad sea capaz de respetar los principios de justicia, sean estos o no los que Rawls propone (Massini, 2000).

“[...] El artificio inventado por Rawls para lograr que un conjunto de personas carentes de virtud y meramente autointeresadas pasen a comportarse inexorablemente de modo justo, no es sino el mismo ya esbozado por los contractualistas ilustrados o preilustrados: Hobbes, Locke y Rousseau; según esta fórmula, un conjunto de individuos perversos (Hobbes), autointeresados (Locke) o anárquicos (Rousseau), pasan a comportarse según principios de justicia solo en virtud de las cláusulas del acuerdo que los lleva a la sociedad. Tampoco en estos casos es necesaria la existencia de virtudes personales en los contratantes: basta con la fórmula del pacto, con el tenor de las cláusulas, para que la sociedad resultante devenga justa, segura y libre. Se trata en definitiva de una fórmula peculiar que une un pesimismo antropológico con un optimismo social, y conforme a la cual el mero modo o forma de ordenar la vida pública de hombres injustos, o al menos no necesariamente justos, hace que el resultado de esa ordenación sea una sociedad justa; para decirlo con palabras de Bertrand de Jouvenel, se trata de la insólita pretensión de alcanzar una sociedad justa sin que nadie tenga que serlo. $\mathrm{O}$ como afirma Vicenzo Vitale, la cuestión que se plantea es la de saber cómo la pura forma puede servir para enmascarar el más negativo de los arbitrios, aquel que en sí mismo no puede ser justificado" (de Jouvenel, 1957, 296).

5. La metaética expuesta por Rawls padece una enorme debilidad e insuficiencia, debido a su "rechazo ontológico", ya que Rawls no hace referencia alguna en su teoría a la realidad intrasubjetiva como instancia de apelación de los principios que sostiene en su ética y teoría de la 
justicia. En esto, Rawls se conforma con remitirse a la coherencia interna entre las premisas, mediante meros procedimientos argumentativos. En esta posición, Rawls no consigue evadirse de la línea general que sigue actualmente la ética contemporánea, la cual solo requiere un tipo de objetividad inmanente, rechazando así fundar su objetividad moral en las estructuras de la realidad que permite alcanzar el conocimiento.

6. Los principios de justicia no pueden ser evaluados mediante un baremo exterior a los principios mismos. El deontologismo rawlsiano reclama una justificación basada en la racionalidad del procedimiento mismo seguido para alcanzar tales principios. La corrección de los juicios, finalmente termina siendo juzgada por el equilibrio o balance de nuestras intuiciones más firmes. Al no alegar ningún mecanismo capaz de convalidar tales intuiciones, los principios acaban dependiendo en cuanto a su convalidación de intuiciones gratuitas que, aunque compartidas, carecen de un fundamento objetivo riguroso. El coherentismo rawlsiano no se puede considerar como un fundamento, pues al apoyar una intuición sobre otra y esta, a su vez, en la anterior (crítica desarrollada por Ricoeur, 1990), Rawls incurre en el vicio de la circularidad demostrativa. La objetividad rawlsiana termina siendo un mero artificio ingenioso, como dirá Massini Correas (2000).

\section{Dimensión ético-normativa ${ }^{14}$}

1. La sociedad bien ordenada que Rawls propone, ¿̇será justa aun cuando su autor haya dejado de lado en su concepción de la justicia al mérito y al carácter de los bienes que se supone han de distribuirse? ¿Es lícito y laudable dejar de lado las cuestiones de mérito personal a la hora de repartir los bienes primarios? ¿Cómo puede ser retribuido de igual manera -o peor aún, en grado superior al menos favorecido-, al aplicar el principio de diferencia en la distribución, a quién, habiéndose esforzado más, realizó una doble medida de un trabajo semejante en el mismo tiempo que otra persona menos favorecida físicamente ${ }^{15}$ Por más que

\footnotetext{
${ }^{14}$ En lo que sigue, seguiremos también de cerca algunos de los aspectos críticos pertenecientes a la ética normativa rawlsiana, que Carlos I. Massini Correas expone en su último artículo publicado sobre la ética jurídica del filósofo de Harvard: "Del positivismo analítico a la justicia procedimental: la propuesta aporética de John Rawls", 199-206; en este caso hemos tomado algunos elementos de su evaluación crítica, con el agregado de otros, basados en diversos autores.

${ }^{15}$ Walzer, M. (1997) Las esferas de la justicia. Una defensa del pluralismo y la igualdad. Trad. de Heriberto Rubio, primera reimpresión (Buenos Aires: F.C.E.), "El merecimiento", 36-37; “El cargo", 140-159; "El reconocimiento: Una sociología de los títulos", 260-269; “Honor público y merecimiento individual”, 269-278.
} 
se alegue que alguien está menos dotado en cuanto a talentos naturales, ya sean físicos o intelectuales, ¿no resulta chocante a la razón humana que se premie más y mejor a quien habiendo producido menos, ya sea cuantitativa o cualitativamente hablando, que a quién más se esforzó en lograr una mayor o mejor producción u original creación? Una manera de tratar como está la distribución de bienes en la sociedad, según este estilo de compensaciones, ¿no alienta la mediocridad, dado el hecho de que quien menos se esfuerce por mejorar su carácter, sus habilidades, sus actitudes y aptitudes, terminará siempre recibiendo una retribución, sino igual a lo que reciben quienes más se hayan esforzado, hasta mejor aún que la que ellos reciben? Pensemos en el ámbito educativo, especialmente universitario, ¿sería lícito y justo, que aquellos que habiéndose preparado mejor en el estudio de sus asignaturas, y habiendo obtenido una cualificación muy buena como potenciales profesionales en sus respectivas líneas, reciban, por ejemplo, durante el transcurso de su carrera iguales o menores calificaciones que los que menos se hayan esforzado? 0 , análogamente, ¿que no tengan acceso a los mejores puestos de trabajo, aun siendo los más capacitados para ejercer semejantes cargos de responsabilidad, porque el principio de diferencia indica que hay que favorecer a los menos dotados o menos calificados? Incluso, llevando este caso al límite de lo imprevisible, que quienes tengan los mejores talentos, dotes naturales o cualidades signadas por el esfuerzo y la perseverancia, ¿reciban asignaciones de cargos o puestos sustancial y cualitativamente inferiores frente a quienes no tienen tantos dotes, sean estos naturales o logrados mediante el esfuerzo y la dedicación personal? ¿A qué clase de sociedad se estaría aspirando con este concepto operativo de justicia social y económica? ¿Semejante mediocridad - alentada por los mecanismos legales y económicos que rigen la supuesta "sociedad bien ordenada" - no irá reproduciendo paulatinamente sociedades cada vez más degradadas en términos de conocimiento, capacidad para resolver problemas, inteligencia operativa, desinterés por la búsqueda de la verdad, tanto cognoscitiva como éticamente, y hasta incluso corrupción moral debido al desaliento de una voluntad perfectiva en materia ética y jurídica? Otorgarles a estas personas ciertas ventajas adicionales por el mero hecho de que dispongan de menos capacidades que los otros, constituye un acto de injusticia para con los restantes. La teoría de la justicia como imparcialidad no toma en cuenta el hecho de los méritos y títulos cuando distribuye bienes (Marion, 1978; Daniels, 1978). 
2. Además queda la permanente duda, a los fines de poder aplicar el criterio del principio de diferencia, sobre cómo es posible saber quiénes son los más desfavorecidos. ¿Cómo se logra medir el grado y la cualificación del tipo de desfavorecimiento natural con que viene cada ser al mundo, cuando se han borrado del ámbito de la justicia - y de la teoría éticaotras variables que permitirían medir estos hechos, por comparación, ya sea transversal y longitudinal, pero que requieren una aceptación de las virtudes como constituyentes esenciales de la vida moral y elementos modificadores de la puesta en ejercicio de la virtud de la justicia? Asimismo, ¿qué papel jugarán la historia vital y la tradición a las que los seres más desfavorecidos pertenecen a la hora de distinguir el grado de desfavorecimiento de que cada uno ha sido dotado, ya sea natural o artificialmente?

3. Una tercera cuestión se refiere a la naturaleza de los bienes a distribuir. Esto, como bien lo expresa Walzer $(1997)^{16}$, no puede ser dejado a un lado cuando se decide establecer un criterio de distribución. Algunos, entre los bienes existentes, como por ejemplo el bien de la salubridad, deberán ser distribuidos según el criterio de necesidad y no de acuerdo con los criterios que prevalecen en el ámbito económico, y así ocurre con bienes tales como el honor individual o colectivo, la santidad personal, la educación, etc. Esta diversidad de bienes no es tomada en cuenta por los criterios, puramente procedimentales, de la justicia rawlsiana.

4. Ciertos autores han denominado al principio de la diferencia como "una obra maestra del conformismo liberal", porque plantea la exigencia de que los más desfavorecidos tengan que aceptar el orden - statu quoexistente, bajo la amenaza de que, de no hacerlo, caerían en peor situación. Este mismo tipo de objeción, ya fue expresada por el propio Hegel, hacia 1821, en el parágrafo 244 de su Filosofía del Derecho, por entonces formulando una crítica a la sociedad capitalista liberal de su época. Algo semejante hizo Herbert Hart, aunque ya directamente dirigiéndose a los principios de Rawls, cuando criticó duramente la primacía del principio de la igualdad liberal, por acarrear resultados del tipo que estamos mencionando. El principio puede conducir a resultados injustos, porque, bajo el pretexto de que se actúa en beneficio de los menos

\footnotetext{
${ }^{16}$ Véase: Walzer, M. (1997). “Una teoría de los bienes”, en Las esferas de la justicia. Una defensa del pluralismo y la igualdad, $19-24$.
} 
aventajados, pueden ser introducidas - o al menos toleradas - hasta las grandes desigualdades sociales. Así, Alain Boyer, dirá que se trata de "una maquinaria ideológica compleja ordenada a legitimar las desigualdades sociales en el marco de la sociedad capitalista contemporánea" (Boyer, 1988, 52).

5. Otro aspecto a resaltar es el divorcio tajante que existe entre las reglas de la justicia procedimental con las concepciones que los seres humanos sostienen sobre el bien. Es este un aspecto central por el cual se definen como "liberales" las doctrinas éticas. Esto es lo que Maclntyre ha llamado "la privatización del bien", y que está implícita en la teoría rawlsiana de la justicia como imparcialidad. Como hemos visto, Rawls no acepta dentro de su teoría a las nociones del bien humano, las cuales son juzgadas por él como falsas, más aún aquellas que expresan un bien humano común. Al respecto afirma Maclntyre:

“[...] los compromisos respecto de la elaboración, defensa y vivencia de las concepciones particulares del bien humano son, desde este punto de vista liberal, asignadas y restringidas a la esfera de la vida privada de los individuos, en tanto lo concerniente a aquello que se considera como reglas morales requeridas por cualquier persona moral, pueden ser legítimamente buscadas solo en el terreno público [...]; el bien ha sido privatizado" (MacIntyre, 1990).

John Rawls - dice Massini Correas - es un caso emblemático de la privatización del bien que denuncia aquí Maclntyre y que aparece, en general, en las doctrinas liberales. Según Rawls, todo bien es subjetivo - depende de deseos y elecciones individuales- y por tanto ha de ser privativo de un individuo particular. Por ello, de acuerdo con esta interpretación que Rawls hace del bien, no puede existir un bien para la comunidad de los seres humanos, pues esto significaría una imposición heterónoma del bien privado de un sujeto o grupo de estos, al resto de los sujetos autónomos, y tal imposición, según Rawls, resultaría siempre injusta. Por ello es que la moralidad, sin posibilidades de asir una idea del bien, deberá reducirse, entonces, a los principios - rawlsianosde la justicia. El liberalismo deontológico rawlsiano se define como tal, precisamente por no aceptar ninguna idea del bien que no esté subordinada a la idea de justicia, tal como comenta Sandel, interpretando 
la posición deontológica de Rawls, en su obra El liberalismo y los límites de la justicia. De todos modos, muestra también allí Sandel, cómo el liberalismo deontológico de Rawls termina negándose a sí mismo, puesto que a pesar de todas sus negativas de aceptar con prelacía una concepción del bien para el hombre y para la unidad social, existen en su concepción de la justicia - y están claramente presentes en supuestos y dispositivos artificiales, tales como la posición original, el velo de ignorancia, los bienes primarios, la neutralidad misma de las concepciones del bien, etc. - , determinados contenidos que representan una clara idea asumida del bien, contenidos que penetran de contrabando en la concepción de Rawls y de los que no se da cuenta, como presupuestos que existen implícitamente y con preterición en su teoría.

6. Otra de las dificultades que presenta la teoría de Rawls consiste en la ausencia, que hay en Rawls, de una consideración del sentido y de la finalidad del obrar humano. Esto dificulta la posibilidad de que la ordenación normativa del obrar quede racionalmente justificada. No hay en Rawls una respuesta coherente sobre el para qué debe actuarse de determinada manera. Al faltar esta, y su consecuente respuesta, Rawls hecha mano de un artificio, ficticio, mediante el cual se producirá el acuerdo voluntario entre las partes que aparece, entonces, exento de justificación racional.

7. El hecho de centrar la justicia y sus principios en la autonomía y el autointerés, haciendo a un lado toda referencia a bien humano alguno, y a partir de tal postulado pretender lograr con tales motivaciones - esencialmente desinteresadas en los otros- una sociedad bien ordenada, justa ${ }^{17}$. Resulta difícil de creer que algo así pueda prosperar, ya que por regla general, el autointerés - como ocurre en el contractualismo hobbesiano- no tiende a lograr una situación de igualdad legal en materia de derechos, prerrogativas y deberes, sino que, contrariamente a esto, más bien tiende hacia la desigualdad y un reparto desigualitario de bienes, produciendo, así, su acumulación. “Existen pocas posibilidades de que una ficción como la de la posición original pueda cambiar

17“Los conflictos no están abordados, en absoluto, a partir de estas divergencias de intereses ni, con mayor razón, a partir de las formas sociales estructurales sobre las que se constituyen, sino más bien a partir del antagonismo que se supone entre doctrinas rivales. La cuestión de la injusticia, en sentido socioeconómico, pasa a segundo plano. Y, la de la instauración de una sociedad justa, se trata en términos de un estudio de las condiciones de una sociedad estable. El problema no consiste ya en transformar el mundo, sino en estabilizarlo". Bidet, John Rawls y la teoría de la justicia, 124. 
radicalmente los rasgos fundamentales de la condición humana" (Massini Correas, 2000).

8. Se observa en Rawls un reduccionismo de la vida ética, ya que las virtudes quedan relegadas al solo principio de la justicia, que tampoco es en Rawls una virtud, sino un artificio sin vida, alcanzado imperfectamente por una serie de meros procedimientos y sin el apoyo de ninguna de las restantes virtudes que han de regir la vida moral. Además, en relación con tal reduccionismo de la moral al ámbito exclusivo de la justicia, hace de la convivencia algo opaco, empobrecido, pues faltan aquí las demás virtudes que deben acompañar a la justicia en el correcto desarrollo de la vida social en común. Estas virtudes son la amistad, la caridad, la piedad, el respeto, la afabilidad, etc., que eran integradas en la comunidad y en los individuos por el pensamiento clásico. Este hecho ha sido un efecto de la acción de la filosofía postilustrada, la cual abandonó paulatinamente las virtudes éticas personales que apuntaban al logro de la perfección humana y social, para dejar a la ética relegada a mera garantía de la convivencia interesada, convivencia que era capaz de mantenerse por una regulación de su accionar mediante principios normativos. Con Rawls, más claramente que en cualquier otro filósofo contractualista, se ha producido un reduccionismo de toda la ética al ámbito de la justicia estricta, donde unos sujetos, que poco y nada se conocen entre sí $-\mathrm{y}$ que son mutuamente desinteresados - basan sus interrelaciones en un marco estrictamente jurídico-político. Con ello, Rawls terminará cargando a la justicia con una serie de tareas que clásicamente no le correspondían, como por ejemplo la igualación de las personas mediante el otorgamiento de bienes y beneficios donde se desconocen los méritos o títulos. Esta nueva tarea de la justicia resulta excesiva, además de extremadamente difícil de lograr dentro de un contexto como el que presentan las sociedades liberales actuales, donde el individualismo extremo está a la orden del día y ha sido sistemáticamente excluida la creencia en la existencia del bien de la comunidad (Maclntyre,1992; Rice, 2001).

9. La teoría de la justicia de Rawls, al pretender justificar ante las conciencias individuales el ideario que constituye la esencia o núcleo central del liberalismo socializante, asume, así, un carácter marcadamente ideológico. Esto ha sido asumido por el propio Rawls, al limitar su teoría al ámbito de las democracias liberales, pretendiendo de este modo zanjar, 
con criterio absolutamente exclusivista, las controversias que perviven en sociedades que poseen este signo y que persisten en, y a partir de, tales condiciones. Por esta razón Chaim Perelman concluirá en relación con la teoría de Rawls que esta no es más que una "elaboración filosófica de la ideología del liberalismo progresista de la sociedad americana de nuestros días" (Perelman, 1984, 211).

"Ahora bien, ese ideologismo y la consiguiente sectorización del pensamiento, no contribuyen a otorgar a las propuestas de Rawls la objetividad y universalidad que requieren las proposiciones de la filosofía, inclusive $-y$ en este caso especialmente - de la filosofía práctica. Pero sin esa pretensión de objetividad y universalidad, la teoría de Rawls resultará aceptable solo para aquellos que compartan su particular concepción ideológica y por el único hecho de compartirla (Massini Correas, 1983); el intento de otorgar valor objetivo y, por ello, intersubjetivo, a las propuestas y modelos de la convivencia política, queda en este caso frustrado y reducida toda la alambicada construcción rawlsiana a una pretensión justificatoria sectorial e inevitablemente parcialista"(Massini Correas, 2000, 210).

En definidas cuentas, la teoría de la justicia como imparcialidad, de John Rawls, solo termina sirviendo a un grupo sesgado de la totalidad de seres humanos que conforman la sociedad: los sujetos liberales.

\section{Epílogo}

Si bien la teoría rawlsiana de la justicia se inscribe en una "tradición moderna", la fuerte tendencia política que la domina, a partir de una concepción puramente política instrumental de los valores éticos, la sitúa -técnicamente- dentro de un esquema cuasi postmoderno de la ética, caracterizado, en el caso de John Rawls, por la circunstancia de que su doctrina moral (procedimental y deontológica) sirve a su concepción de la política y está ordenada al servicio, particularmente en su caso, de la ideología liberal.

Hemos señalado esto al haber tenido en cuenta los siguientes aspectos:

1. No debe ser pasada por alto la cuestión de que en el último Rawls (si nos es permitido hablar de este modo) su concepción de la justicia se orienta políticamente. Rawls hace un claro esfuerzo por acercarse al comunitarismo, habida crítica mediante sus principales representantes, a partir del tema del consenso traslapado; con ello se torna relativista y se aleja del universalismo. 
2. Es una teoría dirigida al ciudadano y no al hombre, porque es el ciudadano, y no el hombre, quien responde ante la ley.

3. Pero aún así, no todo ciudadano puede asumir el marco rawlsiano, que se aplica solo a cualquier comunidad política que coincida con ese tipo de comunidad cultural. Quedan afuera diversas concepciones. Su teoría sirve y es operativa solo en sociedades de vieja tradición democrática y de fuerte homogeneidad cultural.

4. Del parágrafo 3: "The Main Idea of the Theory of Justice" ["La idea principal de la teoría de la justicia"] de su obra fundamental $T J$, se desprende la idea de que posiblemente Rawls esté intentando que el capitalismo liberal se desarrolle de la manera más "aceitada" posible, sin riesgos de revolución ni reforma grande alguna, ni oposición fuerte, ya que mediante la "cooperación interesada" de los sectores menos aventajados sería posible el desarrollo libre de las ganancias de los más aventajados, quienes no encontrarían resistencia, ya que el incremento de sus ganancias traerían, simultáneamente, mejoras (seguramente no ya de ganancias, sino de medios de subsistencia y dignidad) en los sectores menos favorecidos, dependientes de aquellos. El primer principio de la justicia apoyaría tal situación y, el segundo, mostraría los límites y cuidados que se deben tener.

A pesar de todo, existen ciertos beneficios, aunque relativos, en la posición rawlsiana, que merecen ser mencionados, a fin de poder establecer una equilibrada valoración: 1) el establecer principios formales, procedimentales de la justicia, le permite atender las exigencias de una sociedad democrática, pluralista, donde han de caber diferentes concepciones del bien, por eso la prioridad del Right, sobre el Good; 2) de tal manera se podrán evitar los juicios de contenido contradictorio a la hora de establecer principios de justicia y luego acciones tendientes a materializar disposiciones.

Para finalizar, queremos consignar una última evaluación acerca de la idea rawlsiana de imparcialidad, foco neurálgico de su teoría liberal de la justicia.

En relación con este supuesto de la imparcialidad, atributo pretendido por Rawls para sus dos principios de justicia, como así también para la posición original, velo de la ignorancia mediante, cabe señalar que se trata de una condición utópica, por demás, ya que existe escasa probabilidad 
- por no decir ninguna- de ser alcanzada. Por tanto, el hecho de que se diga que se trata aquí de una situación pura y absolutamente hipotética, no basta, pues de qué serviría armar toda una teoría y una doctrina a su servicio si se sabe de antemano que la situación - dado el carácter esencial y ontológico que posee la persona, como ser tanto racional, como afectivo, sentimental y espiritual- no podría darse jamás. Como consecuencia quedan socavados, entonces, los más profundos cimientos de una teoría que, de movida, se presenta anclada en la idealidad pura de la imaginación. Al respecto dice Iris Marion Young:

“El pensador imparcial debe, además, ser desapasionado, abstraerse de sus sentimientos, deseos, intereses y obligaciones que él o ella pueden haber estimado en la situación, o que otros puedan tener. El pensador imparcial es, finalmente, un pensador universal. El punto de vista moral se abstrae de cualquier situación de parcialidad provocada por afiliaciones, de sociedades o de perspectivas grupales, que constituyan objetos concretos" (Marion, 1990).

Filósofos como Adorno y Derrida - señala Young - han expuesto las fallas a las que se exponen argumentos semejantes al de Rawls sobre la posición imparcial de los sujetos, especialmente en relación con los reclamos de la razón misma que rechaza la reducción de las diferencias a una unidad.

"Nadie puede adoptar un punto de vista que sea completamente impersonal y desapasionado, completamente separado del contexto particular y de los compromisos y obligaciones adquiridas. Buscar algo semejante a una noción de razón moral en filosofía es utópico; como afirma Nagel, la posición imparcial es el punto de vista de nadie. [...] El ideal de la imparcialidad es una ficción idealista. Resulta imposible adoptar un punto de vista moral no situado, y si un punto de vista está situado, entonces este no puede ser universal, este no puede permanecer apartado de los asuntos morales sustantivos sin alcanzar la comprensión de la sustancia, en torno a la cual siempre es presupuesto algún contexto particular, social o histórico [...]" (Marion, 1990, 103, 104).

El deseo de construir una razón moral imparcial no resulta en la obtención de una unidad, sino de una dicotomía, puesto que las situaciones cotidianas en que estamos inmersos en nuestra vida, antes que orientarnos hacia la búsqueda de una razón universal, totalizando así nuestra existencia, nos conduce a apreciar y evaluar cada situación de acuerdo con su contexto de acción, en el cual juegan un papel primordial las particularidades de la historia 
particular, nuestras filiaciones y los valores que hemos preconcebido. El ideal de imparcialidad reconstruye este contexto moral dentro de la oposición entre sus aspectos formalmente imparciales y aquellos otros aspectos que son meramente parciales y particulares. Como puede ser percibido, la razón imparcial también genera una dicotomía entre razón y sentimientos; pero esta dirección encaminada hacia la unidad fracasa, porque los sentimientos, los deseos los compromisos y obligaciones no cesan de existir ni de motivarnos, debido a que hayan sido excluidos de una definición de la razón moral. "Estos lucen como sombras inarticuladas aguardando bajo el reclamo de una comprensión de la razón universal. [...] El ideal de imparcialidad expresa el hecho de una imposibilidad, una ficción" (Marion, 1990, 103).

Fernando Aranda Fraga Universidad Adventista del Plata email: decanofhecis@uap.edu.ar

Recibido: 23 de marzo de 2013 Aceptado: 26 de mayo de 2013 


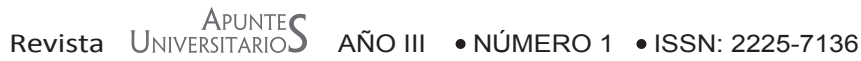

\section{Referencias}

Bidet, J. (2000). John Rawls y la teoría de la justicia. Pamplona: Belaterra.

Boyer, A. (1988). La Théorie de la Justice de John Rawls. En (n.d.), Lectures Philosophiques-1Ethique et Philosophie Politique. Paris: Odile Jacob.

Bellah, R., Madsen, R., Sullivan., W., Swidler, A. y Tipton, S., (1982). The Good Society. New York: Vintage Books.

Boucher, D., Kelly, P. (1994). The Social Contract From Hobbes to Rawls. Routledge: London.

Daniels, N. (1978). "Merit and Meritocracy", Philosophy \& Public Affairs, 7 (Spring), 206-223.

De Jouvenel, B. (1957). La soberanía (Trad. L. Benavídez). Madird: RIALP.

Höffe, O. (1988). Estudios sobre la teoría del derecho y la justicia (Trad. J. Saña). Barcelona: Alfa.

Höffe, O. (1988). Rawls, Kant et l'idée de la Justice Politique. En L'etat et la justica. John Rawls et Robert Nozick. Paris: VRIN.

Höffe, O. (1996). Kant ( Trad. Diorki). Barcelona: Herder Kaufmann, A., (1992). La filosofía del derecho en la posmodernidad. Bogotá: Temis.

Kaufmann, A. (1994). En torno al conocimiento científico del derecho. Persona y Derecho, 31: 19.

MacIntyre, A. (1990). The Privatization of Good. An Inaugural Lecture. The Review of Politics, 42, 3: 346.

MacIntyre, A. (1992). Justice as a Virtue: Changing Conceptions. En Avineri \& de- Shalit (Eds.), Communitarianism and Individualism. Oxford: O. U. P.

Marion, I. (1978). Justice and the Politics of Difference, "Affirmative Action and the Myth of Merit". Philosophy \& Public Affairs, 7 (Spring), 206-223.

Marion, I. (1990). Justice and the Politics of Difference. Princeton, New Jersey: Princenton University Press.

Massini, C. (1983). El renacer de las ideologías. Mendoza: EDIUM.

Massini, C. (2000). Justicia y derecho en ley natural y derechos naturales de John Finnis. Sapientia. LV. 207, 557-568.

Massini, C. (2000). Del positivismo analítico a la justicia procedimental: la propuesta aporética de John Rawls. Persona y Derecho. 42, 188-199.

Nino, C. (1992). Etica analítica en la actualidad. En V. Camps., O. Guariglia \& F. Salmerón (Eds.), Concepciones de la ética. Madrid: Trotta. 


\section{Fernando Aranda Fraga}

Parkin, G. (1985). English-Speaking Justice. Notre Dame, Indiana: Notre Dame University Press.

Perelman, C. (1984). "Les conceptions concrète et abstraite de la raison et de la justice. A propos de la theorie de la justice de John Rawls. En Jean Ladrière y Philip Van Parijs (Comps.), Fondements d'une theorie de la justice. Essais critiques sur la philosophie politique de John Rawls. Louvain-la-Neuve: Éditions de I'Institut Supérieur de Philosophie.

Puelles, M. (1995). El valor de la libertad. Madrid: RIALP.

Rawls, A. (1971). A Theory of Justice. 21th edition. Cambridge, Massachusetts: Harvard University Press.

Rice, E. (2001). "Combatting Ethical Relativism: Maclntyre's Use of Coherence and Progress". American Catholic Philosophical Quarterly, LXXV, 1 (2001), 61-82.

Ricoeur, P. (1990). John Rawls: de l'autonomie morale à la fiction du contract social. Revue de Métaphysique et de Morale, 3, 367-384.

Sandel, M. (1982). Liberalism and the Limits of Justice. New York: Cambridge University Press.

Spaemann, R. (1991). Felicidad y benevolencia. Madrid: RIALP.

Vitale, V. (1988). ¿Pureza o imperfezione? Critica ad un'idea di giustizia procedurale pura. En AA. VV. En F. D’Agostino (Ed.), Materiali sul neocontrattualismo. Milano: Jaca Book.

Walzer, M. (1997). Las esferas de la justicia. Una defensa del pluralismo y la igualdad (Trad. H. Rubio). Buenos Aires: F.C.E. (Primera reimpresión). 